\title{
Influence of Elastic Recovery Time on the Dimensional Stability of Polydimethylsiloxane (PDS)
}

\author{
Leonardo de Cesero, Lígia Maria Nogarett, Eduardo Gonçalves Mota, Lisiane Martins Fracasso \\ Graduate Program in Dentistry, Pontifical Catholic University of Rio Grande do Sul, PUCRS \\ Carlos dos Reis Pereira de Araujo \\ Graduate Program in Dentistry, University of São Paulo, USP
}

\begin{abstract}
The aim of this study was to determine the influence from the recovering time on the dimensional stability of polydimethylsiloxane (Speedex, Coltène/Whaledent Company, Altstätten, Switzerland) prior to type IV dental stone pouring. The double impression technique was utilized with uniform spacing of $1 \mathrm{~mm}$ for the wash paste, at 30 minutes, 24 hours and 72 hours after making the impression using an individual perforated metal tray. After the preparation of the impressions, six stone models were made by the standard procedure for all the impressions. The dimensional alterations ( $\mathrm{mm}$ ) of the models obtained were submitted to analysis of variance (ANOVA) and Tukey's test $(\alpha=0.05$ ). No statistically significant difference between the three groups (30 minutes, 24 hours and 72 hours) were recorded for either the height or diameter of the samples. However, upon comparing the results of the three groups with the metal standard model, there was a significant difference between group $1(30 \mathrm{~min})$ in relation to the diameter of the standard metal die $(\mathrm{p}=0,047)$. The condensation silicone Speedex shows satisfactory dimensional stability, where dental stone models can be poured with assurance up to 72 hours after preparation of the impression.
\end{abstract}

Keywords: Dental materials, dental impression materials, elastomers.

\section{Introduction}

A prosthetic rehabilitation will show a satisfactory final result so long as the dentist follows carefully the different necessary steps, from the planning up to the final cementing ${ }^{[1-3]}$. The impression of the supporting teeth and of the adjacent structures is important due to their strategic value, because it represents the transfer of the clinical situation to the laboratory in the form of articulated models ${ }^{[4-8]}$. If this transposition is not realized in an accurate manner, it will be almost impossible for the dentist to carry out a prosthetic rehabilitation that meets the particular specific requisites that will guarantee its long-term longevity, in harmony with aesthetics, the periodontum, pulp and other components of the masticatory system. Therefore, we must always reproduce, with the greatest precision as possible, the situation found in the mouth of the patient ${ }^{[9,10]}$, so that the laboratory work will be executed with greater predictability, always aiming for a better adaptation of the prosthetic pieces. When we do not know the indications of the impression materials, when we neglect the technique recommended by the manufacturer or do not abide by the technical steps of manipulation and proportion, we will have an imprecise impression, damning all future work, clinical as well as laboratory.

Polymers are used in different areas ${ }^{[11]}$ and have fundamental importance in dental impression, restorative and prosthetic materials. Among the existing options of elastomers on the market are the condensation silicones, which are characterized by problems with dimensional stability, due to the release of volatile byproducts, originating from the polymerization process ${ }^{[12-16]}$. To obtain the maximum precision, it is necessary that the die model be made in the first 30 minutes after removal of the impression from the mouth. Efforts have been made by the manufacturers to improve the dimensional stability of condensation silicone and thereby its fidelity in the reproduction of the structures to be cast. According to Alian and Powers ${ }^{[17]}$, the condensation silicone Speedex is described as a material of the last generation by having in its new formula a pre-condensed dimension controller (DCP), which guarantees a greater flexibility, elastic recovery and dimensional stability for many days. Thus, the objective of this study was to investigate the influence of the pouring time of type IV dental stone on the dimensional stability of condensation polymerizing silicone at 30 minutes, and 24 and 72 hours after making the impression.

\section{Experimental}

\section{Material and adjustment of the impression device}

The material utilized in this study and the pouring times of the impressions are found in Table 1.

All materials were manipulated according to manufacturer's specifications. Speedex putty (batch \#0203046) has a working time of 90 seconds and setting time of 5 minutes in the oral cavity. The proportioning of the base paste and catalyst was done by weight, utilizing a digital precision scales (Adventurer, Toledo, São Bernardo do Campo, São Paulo, Brazil). In all the impressions, $4 \mathrm{~g}$ of putty were used per $1 \mathrm{~cm}$ of catalyst paste, measured with a ruler. Handling and placement inside the tray were done manually. 
Speedex wash, a low-viscosity fluid type, presents a working time of 90 seconds and setting time of 5 minutes in the oral cavity. The material comes in the form of two tubes, one with the fluid paste (base paste - batch \#1103660) and the other with catalyst paste (batch \#1103793). The pastes were placed on a glass plate in equal amounts, with the help of a ruler. A quantity of $2 \mathrm{~cm}$ of each paste was utilized and spatulated, using a No. 24 spatula. The fluid material was transferred to the impression with the use of a plastic syringe for elastomers (Polidental, Cotia, São Paulo, Brazil).

The procedures for obtaining the impressions were carried out at room temperature $\left(21 \pm 5{ }^{\circ} \mathrm{C}\right)$. The experimental part of this work was carried out with an impression device optimized by Araujo and Jorgensen $^{[18]}$ (Figure 1), with adaptation of an individual tray (Figure 2), made of a material similar to that of the perforated trays used to make clinical impressions, also with the perforations distributed in a similar manner as in the trays themselves. The die of the metal device has a conical trunk shape, similar to that of a total crown preparation made of stainless steel.

A cylinder positioner $(\mathrm{P})$ was used to center the standard metal die for making impressions. This cylinder allows a spacing of $4 \mathrm{~mm}$ for the impression material, where it was adapted for the standard metal die (MD), and this was fixed on the movable part (MP) by the fixation screw of the die (FS). This die (MD) was separated from the movable part by the auxiliary fixation cylinder of the die. Also in this procedure, the whole assembly (FS, MP, MD and P) was pointed in the direction of the tray $(\mathrm{T})$, supported on the base $(\mathrm{B})$, until the all the

Table 1. Distribution of the groups and times utilized in this study.

\begin{tabular}{ccc}
\hline Group & Material & $\begin{array}{c}\text { Elastic recovery } \\
\text { time prior pouring }\end{array}$ \\
\hline Group 1 & Speedex & 30 minutes \\
Group 2 & Speedex & 24 hours \\
Group 3 & Speedex & 72 hours \\
\hline
\end{tabular}

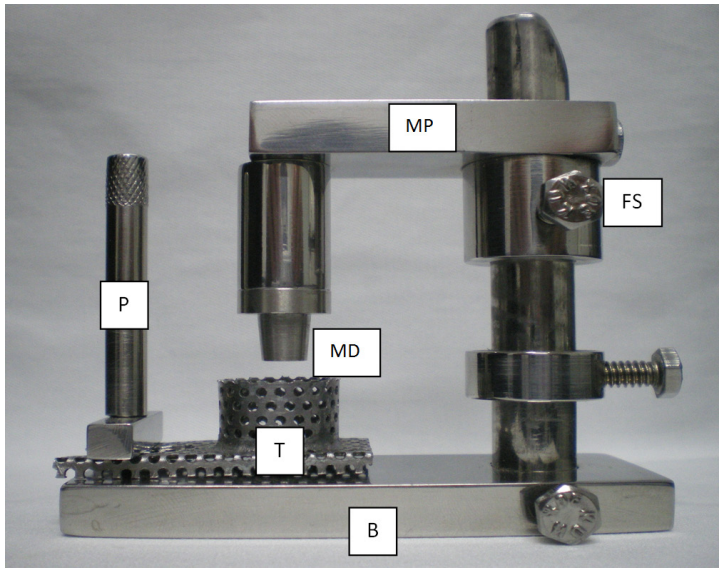

Figure 1. Impression device. Base (B), tray (T), cylinder positioned (P), standard metal die (MD), movable part (MP) and fixation screw (FS). cylinder positioner $(\mathrm{P})$ touched the bottom of the tray $(\mathrm{T})$. At this moment, the die was centered in the vertical and horizontal direction.

Through the ring maintaining the height of the movable part, the positioning of the movable part (MP) was maintained by means of the vertical stem, keeping the height determined by the above procedures. The fixation screw (FS) was then tightened to keep the movable part (MP) at the vertical height obtained, and thus made during the impression procedures.

For this to be centered, the tray (T) was not fixed so that it could be moved in the horizontal direction. After centering the die, the fixation screw of the tray (FS) was tightened to maintain the tray $(\mathrm{T})$ centered and fixed during the impression.

\section{Preparation of impressions and dental stone dies}

The double impression technique was utilized to make the impressions with a uniform spacing of $1 \mathrm{~mm}$ for the wash material, by the use of a metal cylinder.

To make the impression of the metal die (MD), a metal cylinder was placed overlapping the die, providing a thickness of $1 \mathrm{~mm}$ between the putty impression material and the die. The wash paste was manipulated and placed inside the putty mould to make the impression; this was allowed to set. The appearance of the moulds is shown in Figure 3A. All moulds were evaluated critically with respect to the presence of air bubbles or imperfections of details. If these problems occurred, the moulds were discarded and the impressions re-done.

After the impressions were made, dental stone models were made according to the same procedures for all the six moulds, independent of the study group. All impressions after preparation and up to the time pouring were stored at ambient temperature $\left(21 \pm 5^{\circ}\right)$.

The dental stone was poured at the end of the recovering time described in Table 1 for each group, after the setting of the impression material. Type IV dental stone (Durone, Dentsply, York, PA, USA, batch \#343596c) was used for this procedure. Each die was made with $10 \mathrm{~g}$ of dental stone in $1.9 \mathrm{~mL}$ of water, as recommended by the manufacturer. The dental stone was weighed using a digital precision balance and water was measured with a $2 \mathrm{~mL}$ glass pipette (Satelit, Ribeirão Preto, São Paulo, Brazil).

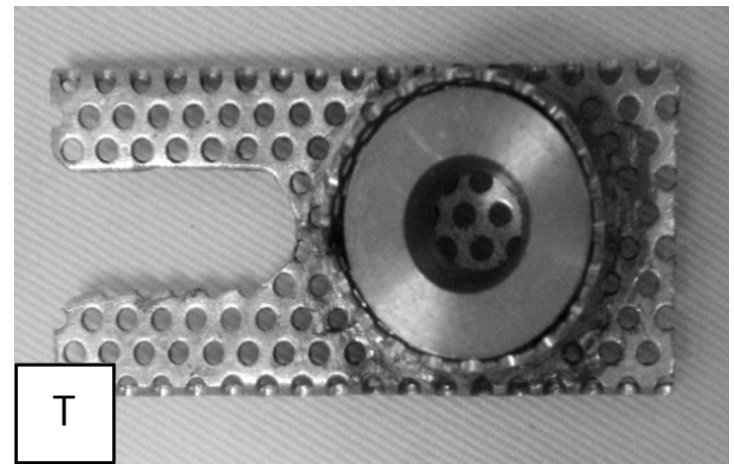

Figure 2. Individual tray (T). 
The dental stone was manipulated according to manufacturer specification under mechanical vibration for 60 seconds. Pouring was done with the help of a vibrator (VH Medical and Dental Equipment, Araraquara, São Paulo, Brazil) and No. 2 brush so that all the surface of the impressions was covered. According to Silva ${ }^{[19]}$, after two hours from spatulation, the dies assume the minimal resistance to be removed from impressions.

All dies were separated, numbered according to each group and stored at room temperature for 24 hours prior dimensional evaluation.

Six dies were made for each group, and their appearance is shown in Figure 3B.

\section{Evaluations of dental stone dies}

The measurements $(\mathrm{mm})$ of the dental stone models were carried out with a 3-D Coordinate Measuring Machine, model BRT - M507, with a precision of 0,001mm (Mitutoyo, Suzano, São Paulo, Brazil). Two measurements were recorded in each model; the first, the height of the preparation, from the base to the highest part, with reference to the center of the die; the second, the diameter of the die, standardized based on the master model, always in middle of the dental stone dies.

Data were tabulated and submitted to ANOVA and tukey $(\alpha=0,05)$ using SPSS sotware (Statistical Package for Social Sciences Version 13.0 for Windows, SPSS Inc., Chicago, Il).

\section{Results and Discussion}

There was no significant difference between groups 1,2 and 3 when compared height and diameter $(p>0,05$; Table 2). However, when each group was compared to the standard metal, there was a significant difference between

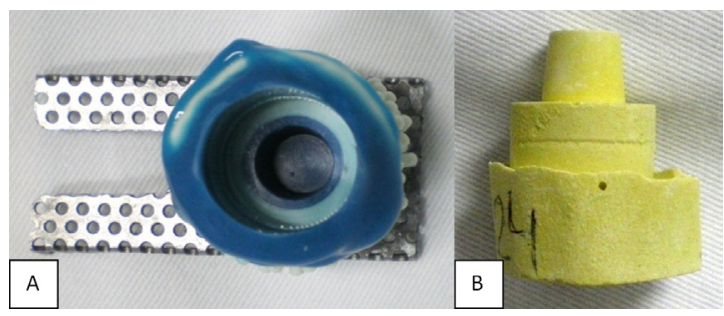

Figure 3. Appearance of mould (A), dental stone die (B). the diameter of group 1 (Speedex $30 \mathrm{~min}$ ) in comparison to the standard die $(p<0,05$; Table 2$)$.

The dimensional stability of any impression material is an important characteristic and has essential clinical repercussions. Manufacturers' condensation silicones have been concerned to some extent in the last years with the improvement of some characteristics of these materials, including dimensional stability, considered a disadvantage of the material. The objective of immediate pouring of the impressions obtained with condensation silicones is to compensate the material's contraction, which occurs due to the evaporation of ethanol, which is a byproduct of the polymerization of the material ${ }^{[20-23]}$.

Currently, in the world market, there are brands of condensation silicone of the last generation in which likely alterations in its formulation produce better results with respect to dimensional stability of the material. The manufacturer of the condensation silicone Speedex recommends in the instructions for use of the low viscosity material (light body) the ideal time of making the dental stone models varies between $30 \mathrm{~min}$ and 7 days after the impression is made.

This study confirms the conclusion by the studies of Lopes, De Cezero and Suzuki ${ }^{[24]}$ who founded dimensional stability in the dental stone models obtained from the condensation silicones Speedex and Zetaplus for pouring times of 30 minutes, 36 hours and 72 hours after the impression was made and Valderhaug ${ }^{[25]}$ that evaluated a condensation silicone at 1 and 24 hours of storage time intervals finding no statistically significant difference between the two groups of materials.

The study done by Kumar et al. ${ }^{[26]}$ compared dimensional stability at immediate pour and multiple pour at the time intervals of 8,16 and 24 hours using the same mould to make all the die casts in different times and the results showed insignificant changes from the standard dimensions at initial pour but as a function of time resulted in production of dies which were shorter in both vertical and horizontal dimensions.

Garrofé et al. ${ }^{[2]}$ founded different results in dimensional stability of Densell, Speedex and Lastic condensation silicones measuring directly on the impression at $0,15,30,60,120$ minutes; 24 hours, 7 and 14 days and obtained difference significant in different times.

The differences found in these studies can be explained by the different methodologies of the studies due to different temperatures employed, measured

Table 2. Comparison of height and diameter between groups and metal standard model.

\begin{tabular}{cccc}
\hline Group & Time & mm & Metal standard \\
\hline Group 1 & 30 minutes & $7,871 \pm 0,040$ & Height \\
Group 2 & 24 hours & $7,874 \pm 0,035$ & 7,900 \\
Group 3 & 72 hours & $7,893 \pm 0,058$ & $p=0,126$ \\
& & $p=0,675$ & Diameter \\
Group 1 & 30 minutes & $7,416 \pm 0,036$ & 7,454 \\
Group 2 & 24 hours & $7,397 \pm 0,061$ & $p=0,070$ \\
Group 3 & 72 hours & $7,401 \pm 0,055$ & $p=0,063$ \\
\end{tabular}


directly on the impression or on a standard die can also determine dimensional changes and different formulas of the condensation silicones Speedex contains a pre-condensed dimension controller (DCP) for the purpose of providing greater flexibility, elastic recovery and dimensional stability for many days, which is not present in other materials. In addition, the methods used in all the studies were different, which can explain the differences found in the results.

Therefore, it is necessary to discuss the clinical significance of our findings. Statistically, a difference was observed in the diameter variable between the groups. The difference between the smallest (group 2, 7,39 mm) and largest diameter (group 1, 7,41 mm) was 0,02 mm, that is, $20 \mu \mathrm{m}$. Such difference would be readily resolved with the use of the spacer whose function is to create a film of cement of approximately $25 \mu \mathrm{m}$.

Based on the described, we can see that this statistical difference $(p=0,047)$ is not clinically important, since it can be eliminated, and thus, clinically, the pouring of the dental stone model can be made up to 72 hours after the impression with the condensation silicone (Speedex).

\section{Conclusions}

Based on the statistical analysis of the results and in accordance with the initial proposal, it can be concluded that the condensation silicone Speedex at times of 30 minutes and 24 and 72 hours, following the proposed method, shows satisfactory dimensional stability, where dental stone models can be poured with assurance up to 72 hours after preparation of the impression.

\section{References}

1. Queiroz, D. A.; Cunha, L.G.; Duarte, J.L.P; Neves, A.C.C. \& Silva-Concílio, L.R. - Braz. Oral Res., 25, p.357 (2011). http://dx.doi.org/10.1590/S1806-83242011005000011

2. Faria, A. C. L.; Rodrigues, R. C. S.; Macedo, A. P.; Mattos, M. G. C. \& Ribeiro, R. F. - Braz. Oral Res, 22, p.293 (2008). PMid:19148382.

3. Greco, G. D.; Goés, I. M. G.; Ferreira, J. C. \& Greco, A. C. D. - Arq. Bras. Odontol., 5, p.53(2009).

4. Devan, M. - J. Prosthet. Dent., 93, p.503 (2005). PMid:15942607. http://dx.doi.org/10.1016/j. prosdent.2005.02.007

5. Silva, S. M. \& Salvador, M. C. - J. Appl. Oral Sci., 12, p.244 (2004). PMid:21049261. http://dx.doi.org/10.1590/ S1678-77572004000300016

6. Samet, N.; Shohat, M.; Livny, A. \& Weiss, E.I. - J. Prosthet. Dent., 94, p.112 (2005). PMid:16046964. http://dx.doi. org/10.1016/j.prosdent.2005.05.002

7. Chen, S. Y.; Liang, W. M. \& Chen, F. N. - J. Dent., 32, p.603 (2004). PMid:15476954. http://dx.doi.org/10.1016/j. jdent.2004.04.002

8. Rubel, B. S. - Dent. Clin. North Am., 51, p.629 (2007). PMid:17586147. http://dx.doi.org/10.1016/j. cden.2007.03.006
9. Balkenhol, M.; Haunschild, S.; Erbe, C. \& Wöstmann, B. - J. Prosthet. Dent., 103, p.288 (2010). http://dx.doi. org/10.1016/S0022-3913(10)60060-1

10. Chugh, A.; Arora, A. \& Singh, V. P. - Int. J. Clin. Pediatr. Dent, 5, p.33 (2012). http://dx.doi.org/10.5005/jpjournals-10005-1131

11. Marcos, H. - Polímeros, 22, p.107 (2012).

12. Fonte-Boa, J. C.; Mota, J. M. L. F.; Poletto, L. T. A.; Carvalho, M. C. F. S,; Cortés, M. E.; Sinisterra, R. D. \& Leal, S. F. - Acta Odontol. Latinoam., 24, p.61 (2011). PMid:22010408.

13. Franco, E. B.; Cunha, L. F. \& Benetti, A. R. - J. Appl. Oral Sci., 15, p.195 (2007). PMid:19089129. http://dx.doi. org/10.1590/S1678-77572007000300008

14. Braden, M. - Biomaterials, 13, p.333 (1992). http://dx.doi. org/10.1016/0142-9612(92)90058-V

15. Papadogiannis, D.; Lakes, R.; Palaghias, G. \& Papadogiannis, Y. - J. Prosthodont. Res., 56, p.11 (2012).

16. Hamalian, T. A.; Nasr, E. \& Chidiac, J. J. - J. Prosthodont., 20, p.153 (2011). PMid:21284760. http:// dx.doi.org/10.1111/j.1532-849X.2010.00673.x

17. Alian, G. A. \& Powers J. M. - J. Dent. Res., 77, p.764 (1998).

18. Araujo, P. A. \& Jorgensen K. D. - J. Prosthet. Dent, 54, p.791 (1985). PMid:3908659.

19. Silva, M. A. B.; Vitti, R. P.; Consani, S.; Sinhoreti, M. A. C.; Mesquita, M. F. \& Consani, R. L. X. - J. Appl. Oral. Sci, 20, p.588 (2012). PMid:23138748. http://dx.doi. org/10.1590/S1678-77572012000500016

20. Antunes, R. P. A.; Matsumoto, W. \& Panzeri, H. - Rev. Odontol. USP, 11, p.263 (2011)

21. Nishioka, R. S.; Landim, K. T.; Mesquita, A. M. M.; Almeida, E. E. S. \& Balducci, I. - Cienc. Odontol. Bras., 7, p.45 (2004).

22. Sinhoreti, M. A. C.; Vitti, R. P.; Mendonça, M. J.; Consani, R. L. X. \& Correr-Sobrinho, L. - RFO UPF, 15, p.139 (2010).

23. Donovan, T. E. \& Chee, W. W. L. - Dent. Clin. N. Am., 48, p.445 (2004). PMid:15172610. http://dx.doi.org/10.1016/j. cden.2003.12.014

24. Lopes, L. A. Z.; De Cezero, L. \& Suzuki R. M. - Rev. Fac. Odontol. Porto Alegre, 47, p.9 (2006).

25. Valderhaug, J. \& Floystrand, F. - J. Prosthet. Dent., 52, p.514 (1984). http://dx.doi.org/10.1016/0022-3913(84)90336-6

26. Kumar, D.; Madihalli A. U.; Reddy, K. R.; Rastogi, N. \& Pradeep N. T. - J. Contemp. Dent. Pract., 12, p. 272 (2011). PMid:22186862. http://dx.doi.org/10.5005/jpjournals-10024-1046

27. Garrofé, A. B.; Ferrari, B. A.; Picca, M. \& Kaplan, A. E. - Acta Odontol. Latinoam., 24, p.289 (2011). PMid:22550824.

Received: $10 / 18 / 12$

Revised: 01/21/13

Accepted: 03/11/13 